\title{
EL CASO BREXIT ANTE LOS JUECES CONSTITUCIONALES DEL REINO UNIDO: COMENTARIOS A LA SENTENCIA DE LA ALTA CORTE DE JUSTICIA DE 3 DE NOVIEMBRE DE 2016, CONFIRMADA POR EL TRIBUNAL SUPREMO EN SENTENCIA DE 24 DE ENERO DE 2017
}

\author{
ALLAN R. BREWER-CARÍAS \\ Universidad Central de Venezuela \\ allanbrewercarias@gmail.com
}

Cómo citar/Citation

Brewer-Carías, A. R. (2017).

El caso brexit ante los jueces constitucionales del Reino Unido: comentarios a la Sentencia de la Alta Corte de Justicia de 3 de noviembre de 2016 , confirmada por el Tribunal Supremo en Sentencia de 24 de enero de 2017. Revista de Administración Pública, 202, 133-156. doi: https://doi.org/10.18042/cepc/rap.202.04

\section{Resumen}

Este comentario tiene por objeto analizar los razonamientos jurídicos constitucionales formulados por la High Court of Justice y la Supreme Court del Reino Unido, basados en el principio de la soberanía parlamentaria y su prevalencia sobre la voluntad popular expresada en el referendo de 23 de junio de 2016, y en el rango constitucional de la European Communities Act de 1972, para imponerle al Gobierno la necesidad de acudir ante Parlamento y obtener su aprobación previa para poder notificar la salida del Reino Unido de la Unión Europea, ejerciendo así un control de constitucionalidad respecto de la amenaza del Gobierno de formular esa notificación con base solo en el ejercicio de sus poderes ejecutivos (prerrogative powers).

\section{Palabras clave}

Soberanía parlamentaria; Unión Europea; control de constitucionalidad; leyes constitucionales; referendo. 


\section{Abstract}

This comment analyzes the constitutional arguments followed by the High Court of Justice and the Supreme Court of the United Kingdom, exercising judicial review upon the intention of the Government to give notice to the European Union for the exit of Great Britain only exercising its prerogative powers, based on the principle of Parliament Sovereignty, its prevalence upon the popular will expressed in the European Union Referendum of 23 of June of 2016, and on the constitutional statute character of the European Communities Act de 1972, imposing the Government the need to request the previous authorization from the Parliament to give such notice.

\section{Keywords}

Parliament Sovereignty; European Union; Judicial Review; Constitutional Statute; Referendum. 


\section{SUMARIO}

I. ALGUNOS PRINCIPIOS DEL CONSTITUCIONALISMO BRITÁNICO. II. EL CASO BREXIT. III. LA CUESTIÓN CONSTITUCIONAL PLANTEADA. IV. LOS PRINCIPIOS CONSTITUCIONALES DEL REINO UNIDO CONSIDERADOS. V. UNA LECCIÓN SOBRE EL DERECHO CONSTITUCIONAL DEL REINO UNIDO: 1.Sobre el principio de la soberanía del Parlamento del Reino Unido. 2. Sobre el tema de los límites de los poderes de prerrogativa de la Corona. VI. LA INTERPRETACIÓN CONSTITUCIONAL Y EL CONTROL DE CONSTITUCIONALIDAD. VII. LA CONFIRMACIÓN DE LA DECISIÓN DE LA ALTA CORTE DE JUSTICIA POR LA CORTE SUPREMA DEL REINO UNIDO. VIII. LA DESESTIMACIÓN DE LOS ALEGATOS SOBRE DEVOLUTION EN RELACIÓN CON LA CUESTIÓN DE LA INJERENCIA DE IRLANDA DEL NORTE, ESCOCIA Y GALES EN LA DECISIÓN SOBRE EL BREXIT.

Una de las decisiones más importantes adoptadas en materia constitucional por los tribunales del Reino Unido ha sido la que la Alta Corte de Justicia dictó el 3 de noviembre de 2016, ratificada por la Corte Suprema del Reino Unido el 24 de enero de 2017, en relación con el caso brexit, es decir, con la salida del Reino Unido de la Unión Europea como consecuencia del referendo que se realizó sobre el tema el 23 de junio de 2016; decisión política que, por lo demás, quizá sea, a su vez, la más importante decisión adoptada hasta ahora en el marco del proceso de la integración regional de Europa, el cual ha sido siempre un proceso político que se ha desarrollado, desde el inicio, de la mano del derecho constitucional ${ }^{1}$.

1 Véase Allan R. Brewer-Carías, "Constitutional Implications of Regional Economic Integration» (General Report, XV International Congress of Comparative Law, International Academy of Comparative Law, Bristol, September 1998), en Allan R. Brewer-Carías, Études de Droit Public Comparé, Bruxelles, Bruylant: págs, 453-522. Véase igualmente Allan R. Brewer-Carías, Las implicaciones constitucionales de la integración económica regional, Cuadernos de la Cátedra Allan R. Brewer-Carías de Derecho Público, Universidad Católica del Táchira, Editorial Jurídica Venezolana, Caracas, 1998. 
Nuestra intención, en esta nota, es dar cuenta del contenido más relevante de dichas decisiones a la luz de los principios del constitucionalismo contemporáneo, en particular en materia de separación de poderes, en lo que se refiere a las relaciones entre el Parlamento y el Ejecutivo, conforme a los principios de la soberanía parlamentaria y de los límites a los poderes de prerrogativa de la Corona en materia de regulación.

\section{ALGUNOS PRINCIPIOS DEL CONSTITUCIONALISMO BRITÁNICO}

Si bien es cierto que el Reino Unido no tiene una Constitución que se pueda encontrar completa en un documento escrito, adoptada por el pueblo conforme a los principios derivados del constitucionalismo moderno ${ }^{2}$, ello no significa que no tenga una Constitución ni que carezca de derecho constitucional. Al contrario:

[...] el Reino Unido tiene su propia forma de derecho constitucional, tal como se reconoce en cada una de las jurisdicciones de sus cuatro naciones constituyentes. Parte de dicho derecho está escrito en forma de leyes que tienen particular importancia constitucional; y otra parte se refleja en reglas legales fundamentales reconocidas por el Parlamento y los tribunales. Se trata de reglas legales establecidas y bien reconocidas que regulan el ejercicio del poder público y que distribuyen la autoridad para adoptar decisiones entre las diferentes entidades en el Estado y definen el ámbito de sus respectivos poderes ${ }^{3}$.

Lo anterior no es algo que haya sido dicho en algún escrito o libro de derecho constitucional del Reino Unido o de derecho constitucional comparado, sino que fue lo expresado por la Alta Corte de Justicia (High Court of Justice, Queen's Bench Division, Divisional Court) del Reino Unido, en su sentencia del 3 de noviembre de 2016 dictada en el caso Gina Miller y otros contra el Secretary of State for Exiting the European Union ${ }^{4}$, para decidir pre-

2 Véase Allan R. Brewer-Carías (2016), Principios del Estado de Derecho. Aproximación Histórica, Cuadernos de la Cátedra Mezerhane sobre democracia, Estado de derecho y derechos humanos, Miami: Miami Dade College, Editorial Jurídica Venezolana International, págs. 38 ss.

3 Caso Gina Miller y otros contra el Secretary of State for Exiting the European Union ((Case No: CO/3809/2016 and CO/3281/2016). Véase el texto de la sentencia en: https://www.judiciary.gov.uk/judgments/r-miller-v-secretary-of-state-for-exiting-theeuropean-union-accessible/

4 Idem. 
cisamente una cuestión de orden constitucional, que no fue otra sino determinar en el orden constitucional de Gran Bretańa si el Gobierno tiene o no posibilidad, ejerciendo sus poderes ejecutivos (Crown's prerrogative powers) y sin la intervención y decisión previa del Parlamento, de decidir notificar a la Unión Europea conforme al artículo 50 del Tratado de la misma, la decisión de la salida del Reino Unido de dicha Unión, en cumplimiento de la recomendación popular expresada en el referendo del 23 de junio de 2016. Dicho referendo se realizó conforme a la Ley que fue aprobada por el Parlamento en 2015 (European Union Referendum Act 2015), sobre la cuestión de si el Reino Unido debía quedarse o salir de la Unión Europea ${ }^{5}$, habiendo sido la respuesta popular dada, como es sabido, que el Reino Unido debía salirse de la misma.

Para decidir la cuestión constitucional planteada, la Alta Corte constató que en el Reino Unido, como democracia constitucional que es, los órganos del Estado están sometidos a reglas de derecho, es decir, al «rule of law» (Estado de derecho), teniendo en consecuencia los tribunales del Reino Unido, en palabras de la propia Corte, un:

[...] deber constitucional que es fundamental al Estado democrático de derecho de imponer las reglas de derecho constitucional de la misma manera como los tribunales imponen otras leyes.

Esta declaración de la Alta Corte es, sin duda, uno de los más claros reconocimientos por parte de órganos judiciales británicos de la existencia de una jurisdicción constitucional en el Reino Unido ${ }^{6}$, con base en lo cual la Alta Corte, ejerciendo poderes de control de constitucionalidad (Judicial Review), constató que, para decidir el caso concreto, había sido requerida precisamente para:

[...] aplicar el derecho constitucional del Reino Unido para determinar si la Corona tiene poderes de prerrogativa (prerrogative powers) para notificar bajo el artículo 50 del Tratado de la Unión Europea, e iniciar el procedimiento de salida de la Unión Europea.

5 Véase en http://www.legislation.gov.uk/ukpga/2015/36/contents/enacted/data.htm. La pregunta formulada en el referendo fue: «Should the United Kingdom remain a member of the European Union or leave the European Union?».

6 A ello me anticipaba hace unos años al estudiar la situación de las cortes constitucionales en el derecho constitucional comparado. Véase Allan R. Brewer-Carías (2010), Constitucional Courts as Positive Legislators in Comparative Law, New York: Cambridge University Press, pág. 25. 
Con todo ello quedó, por tanto, fuera de toda duda, que el Reino Unido tiene una Constitución, como norma suprema que se impone frente a los actos estatales, y que los tribunales tienen competencia para controlar la constitucionalidad de los actos estatales?

\section{EL CASO BREXIT}

El caso Gina Miller y otros contra el Secretary of State for Exiting the European Union que se desarrolló ante la Alta Corte fue, por tanto, un típico proceso constitucional o de control de la constitucionalidad de la acción del Gobierno $^{8}$, en este caso de orden preventivo ante el anuncio oficial del Gobierno británico, hecho público luego del reacomodo gubernamental provocado por el resultado del referendo, de que se procedería a notificar a la Unión Europea la salida del Reino Unido de la misma.

En el proceso, la Alta Corte, para decidir, se basó en la consideración de que la European Communities Act de 1972 (Ley ECA de 1972) ${ }^{9}$, mediante la cual se le dio efectos al derecho comunitario en el sistema legal nacional del Reino Unido, era una ley constitucional a la cual estaba sometido el Gobierno, el cual no la podía modificar en forma alguna mediante el ejercicio de los poderes de prerrogativa de la Corona.

El rango constitucional de dicha ley (constitutional statute), según la Alta Corte, fue confirmado en su momento por la House of Lords en el caso $R \mathrm{v}$ Secretary of State for Transport, ex p. Factortame Ltd [1990] 2 AC 85, considerando que la Ley ECA de 1972 estaba vigente mientras permaneciera en el libro de leyes (statute book), para dar efecto directo y prevalente al derecho de la Unión Europea sobre la legislación primaria doméstica o nacional. Es decir, en virtud de la Ley ECA de 1972, los tribunales nacionales dan pleno efecto al derecho de la Unión Europea como parte del derecho interno que los mismos aplican.

Tal como lo expresó Lawton en el caso Thoburn $v$ Sunderland City Council [2003] QB 151 (DC) at [62], citado en la sentencia: «Es posible

7 Algo que unas décadas atrás no era comúnmente aceptado. Véase Allan R. BrewerCarías (1989), Judicial Review in Comparative Law, Cambridge: Cambridge University Press.

8 Véase en general sobre los procesos constitucionales: Allan R. Brewer-Carías (2015), Derecho Procesal Constitucional. Instrumentos para la Justicia Constitucional, Editorial Jurídica Venezolana International.

9 Véase en http://www.legislation.gov.uk/ukpga/1972/68/contents. 
que nunca haya habido una ley que haya tenido un efecto tan profundo en tantas dimensiones en nuestra vida diaria", considerando a la Ley ECA de 1972:

[...] como una ley constitucional (constitutional statute) que tiene tal importancia en nuestro sistema legal que no está sujeta al amplio principio de derogación implícita por parte de alguna legislación posterior. Su importancia es de tal naturaleza que solo puede ser derogada o reformada conforme a las disposiciones expresas de su texto, mediante una ley subsecuente o como necesaria implicación de sus propias previsiones. En sentido similar, la Ley ECA 1972 fue descrita por Lord Neuberger of Abbotsbury PSC and Lord Mance JSC en $R$ (Buckinghamshire County Council) v Secretary of State for Transport [2014] UKSC 3; [2014] 1 WI.R 324. at [207], como una entre varios instrumentos constitucionales.

Dicha Ley del Parlamento, de rango constitucional, que selló el proceso de incorporación del Reino Unido a las Comunidades Europeas, la cual se materializó el 1 de enero de 1973, se sancionó como consecuencia de la condición establecida en el derecho comunitario de que para que el mismo fuera incorporado en el derecho interno, debía ser aprobado mediante legislación primaria en cada Estado. Como afirmó la Alta Corte en su sentencia:

La Corona no hubiera podido ratificar la incorporación del Reino Unido a las Comunidades Europeas conforme al Tratado de las Comunidades sin que el Parlamento hubiese sancionado una legislación para ello. Una legislación del Parlamento era necesaria para dar efectos al derecho de la Unión Europea en el derecho interno de la jurisdicción del Reino Unido, tal como era requerido por esos Tratados y era necesario para dar efectos en el derecho interno a los derechos y obligaciones derivadas del derecho de la Unión Europea.

El proceso constitucional desarrollado ante la Alta Corte, cuestionando la posibilidad de que el Gobierno solo decidiera la salida del Reino Unido de la Unión Europea, se inició por una ciudadana británica mediante el ejercicio de una acción equivalente a la denominada acción popular de constitucionalidad en los derechos hispanoamericanos ${ }^{10}$, intentada precisamente contra

10 Véase Allan R. Brewer-Carías, "Acción popular de inconstitucionalidad», en Eduardo Ferrer Mac-Gregor, Fabiola Martínez Ramírez y Giovanni A. Figueroa Mejía (coords.), Diccionario de derecho procesal constitucional y convencional, México: Poder Judicial de la Federación, Consejo de la Judicatura Federal, Universidad Nacional Autónoma de México, Instituto de Investigaciones Jurídicas, Serie Doctrina Jurídica, 692, págs. 232-233. 
dicha pretensión del Gobierno de formular la mencionada notificación, cuya legitimación activa fue expresamente reconocida por el tribunal, considerando que la misma correspondía a cualquier persona en el Reino Unido o con ciudadanía británica, quienes podrían ver sus derechos afectados sí la notificación de abandonar la Unión Europea se realizaba. Además de la recurrente en el proceso, concurrieron otras personas y abogados planteando, entre otras, cuestiones relativas a la soberanía parlamentaria; al impacto de la decisión respecto del derecho a la libre circulación conforme al derecho de la Unión Europea, de ciudadanos británicos viviendo en otros países miembros de la Unión teniendo allí acceso a servicios públicos y a cómo quedaría afectado el estatus de inmigración de personas residenciadas en el Reino Unido como resultado de la notificación conforme al artículo 50 .

La defensa del caso se aceptó que lo llevara el secretario de Estado para la salida del Reino Unido de la Unión Europea, considerándolo como el órgano apropiado para actuar en nombre del Gobierno en representación de la Corona, cubriendo así la acción por cualquier otro ministro del Gobierno.

\section{LA CUESTIÓN CONSTITUCIONAL PLANTEADA}

La cuestión que plantearon los recurrentes ante la Alta Corte fue que conforme:

[...] a un principio fundamental de la Constitución del Reino Unido, los poderes de prerrogativa de la Corona no pueden ser utilizados por el gobierno ejecutivo para disminuir o eliminar derechos conferidos por ley, sea conferidos por el common law o por leyes (statutes), salvo que el Parlamento le haya otorgado expresamente autoridad a la Corona o en forma implícita conforme a los términos de un Acto del Parlamento, para disminuir o derogar esos derechos.

Los recurrentes argumentaron además que no es posible encontrar palabra alguna expresa o implícita en la Ley ECA de 1972 o en alguna otra legislación subsecuente relacionada con la Unión Europea, mediante la cual el Parlamento le hubiera conferido dicha autoridad al Ejecutivo para iniciar el proceso de poner término al Tratado de la Unión Europea y que el Parlamento no dio autoridad alguna a la Corona, mediante la Ley del referendo de 2015, para enviar la notificación a que se refiere el artículo 50 del Tratado de la Unión Europea.

Algo que unas décadas atrás no era comúnmente aceptado. Véase Allan R. BrewerCarías (1989), Judicial Review in Comparative Law, Cambridge: Cambridge University Press. 
Se trató, en resumen, como lo calificó la sentencia, de una «cuestión puramente legal» (a pure question of law), que se consideró como completamente justiciable conforme a la Constitución del Reino Unido (justiciable under the $U K$ constitution), la cual, por supuesto, nada tenía que ver con el mérito o demérito de la decisión de dejar la Unión Europea, lo que el Tribunal consideró que era un «tema político» (a political issue ${ }^{11}$ que quedaba fuera de su competencia.

La cuestión justiciable, como deriva de los planteamientos de los recurrentes, fue en definitiva la de determinar si conforme al derecho constitucional del Reino Unido, el Gobierno en ejercicio de sus poderes de prerrogativa de la Corona y sin intervención del Parlamento, podía formular conforme al mencionado artículo 50 del Tratado de la Unión Europea, la notificación oficial de la decisión gubernamental de salir de la misma; partiendo para ello del supuesto, que había sido aceptado por las partes, de que ni la Ley del Referendo de la Unión Europea de 2015, ni ningún otro Acto del Parlamento, le había conferido al Gobierno autoridad legal alguna distinta de los poderes de prerrogativa de la Corona que le pudiera permitir formular la notificación conforme al artículo 50.

Por otra parte, la Corte también precisó que el régimen que rige el proceso comunitario europeo para que un Estado pueda salirse de la Unión Europea, implica que una vez que un Estado notifique su decisión conforme al artículo 50 del Tratado de la Unión, se abre un período de dos años a los efectos de que se negocie un acuerdo de retiro. Dicha notificación, conforme lo aceptó el Gobierno en el proceso, no puede estar condicionada, por lo que no puede formularse sujetándola por ejemplo a la aprobación del Parlamento. La consecuencia de la notificación conforme al artículo 50, una vez que se complete el proceso de salida de un Estado de la Unión Europea, como advirtió la Corte, es la inevitable pérdida para los ciudadanos británicos de algunos derechos consagrados en el derecho de la Unión Europea, que precisamente fueron incorporados en el derecho interno del Reino Unido mediante la mencionada Ley ECA de 1972.

11 La Corte agregó que su decisión «no tiene injerencia en la política gubernamental, porque la política gubernamental no es ley. La política a ser aplicada por el gobierno ejecutivo y el mérito o demérito de la salida son materias de juicio político a ser resueltas a través de un proceso político». 


\section{LOS PRINCIPIOS CONSTITUCIONALES DEL REINO UNIDO CONSIDERADOS}

Para decidir el caso, la Alta Corte analizó los "principios constitucionales» del Reino Unido, destacando lo que calificó como la regla más fundamental de su Constitución (UK's constitution), que es que el Parlamento es soberano y, como tal, puede sancionar y derogar cualquier ley a su elección (that Parliament is sovereign and can make and unmake any law it chooses); siendo un aspecto de dicho principio de la soberanía del Parlamento, establecido desde hace cientos de años, que la Corona - o sea el Gobierno- no puede ejercer poderes de prerrogativa para derogar la legislación sancionada por el Parlamento.

La Corte consideró este principio como de suma importancia al analizar el contexto de la regla general sobre la cual el Gobierno buscó fundamentar su argumento en el caso, que fue la competencia ejecutiva, en ejecución de los poderes de prerrogativa de la Corona, para la conducción de las relaciones internacionales y la suscripción o denuncia de tratados, materias que fueron consideradas que caían dentro del ámbito de dichos poderes de prerrogativa.

Conforme lo consideró la Alta Corte, esa regla general efectivamente existe, pero solo con efectos en el ámbito internacional, no teniendo el ejercicio de dicha prerrogativa efecto alguno en el derecho interno establecido en la legislación sancionada por el Parlamento. Citando lo explicado por Lord Oliver of Aylmerton es su presentación en el Tin Council case, J. H. Rayner (Mincing Lane) Ltd v Department of Trade and Industry [1990] 2 AC 418, at $499 \mathrm{E}-500 \mathrm{D}$, la Alta Corte consideró que:

[...] como principio del derecho constitucional del Reino Unido, la Prerrogativa Real, a pesar de que permite hacer tratados sin la intervención del Parlamento, no se extiende a la posibilidad de alterar la ley, o a conferir derechos a los individuos, o a privarlos de los derechos que gozan en el derecho interno.

De ello, lord Oliver of Aylmerton concluyó con su afirmación principista de que «un tratado no es parte del derecho inglés salvo que haya sido incorporado en el derecho interno mediante legislación».

Por ello, para decidir, la Alta Corte constató - lo que el Gobierno aceptó y argumentó en forma positiva - que, si se formula la notificación conforme al artículo 50, ello inevitablemente tiene efectos cambiantes en el derecho interno, en el sentido de que las disposiciones del derecho de la Unión Europea que el Parlamento hizo parte del derecho interno con la sanción de la Ley de 1972, en su momento cesarán de tener efectos. 
Para contrarrestar este argumento, el principal alegato del Gobierno en el caso fue que debía presumirse que el Parlamento, cuando sancionó la Ley ECA de 1972, tuvo la intención de considerar que la Corona retendría sus poderes de prerrogativa para decidir sobre la salida del Reino Unido de los Tratados de la Comunidad Europea (ahora el Tratado de la Unión Europea), y de considerar que la Corona tendría el poder de escoger si el derecho de la Unión Europea debía continuar o no teniendo efectos en ámbito del derecho interno del Reino Unido. La Alta Corte, en su sentencia, no aceptó este argumento, considerando al contrario que no había nada en el texto de la Ley ECA de 1972 que lo fundamentara, desechándolo y aceptando los argumentos de los recurrentes, tanto con base en el propio lenguaje utilizado por el Parlamento en dicha Ley como en el principio constitucional fundamental de la soberanía del Parlamento, y en la ausencia de poder alguno de la Corona para cambiar la ley interna en ejercicio de sus poderes de prerrogativa.

Con base en estos argumentos, la Alta Corte de Justicia, en su sentencia, decidió que el Gobierno en el Reino Unido no tiene el poder basado en la prerrogativa de la Corona para formular la notificación prevista en el artículo 50 del Tratado de la Unión Europea, para que el Reino Unido salga o se retire de la Unión Europea.

\section{UNA LECCIÓN SOBRE EL DERECHO CONSTITUCIONAL DEL REINO UNIDO}

Aparte de la importancia que la decisión de la Alta Corte de Justicia del Reino Unido tiene para el derecho comunitario europeo y para el futuro de la Unión Europea, la Sentencia del 3 de noviembre de 2016 tiene una importancia muy significativa para los estudiosos del derecho constitucional, particularmente en el derecho continental e iberoamericano, pues la misma es en sí misma, como hemos indicado, una clara lección sobre el derecho constitucional contemporáneo del Reino Unido, en particular en relación con las reglas que rigen las relaciones entre los poderes legislativo y ejecutivo, establecidas con base en los principios constitucionales de la soberanía parlamentaria y de los poderes de prerrogativa de la Corona.

\section{SOBRE EL PRINCIPIO DE LA SOBERANÍA DEL PARLAMENTO DEL REINO UNIDO}

Y, en efecto, como argumentó el Alto Tribunal, la regla más fundamental del derecho constitucional del Reino Unido es el principio de la soberanía del Parlamento, es decir, de «la Corona en el Parlamento» que es el soberano, de 
manera que la legislación sancionada «por la Corona con el consentimiento de ambas Cámaras del Parlamento es suprema».

Como consecuencia de ello, el Parlamento es quien puede sancionar la legislación primaria del Reino Unido y cambiar las leyes en la forma que decida, no existiendo ley alguna que sea superior a la legislación primaria, con la sola excepción de aquellos casos en los cuales el propio Parlamento ha hecho previsión expresa de que así sea; como precisamente es el caso de la Ley ECA de 1972 mediante la cual se confirió precedencia al derecho de la Unión Europea sobre los actos del Parlamento.

Pero incluso en esos casos, el Parlamento permanece siendo soberano y supremo, y tiene todo el poder para remover cualquier autoridad o jerarquía dada a otras leyes mediante la legislación primaria anterior.

En resumen, concluyó la Corte, «el Parlamento tiene el poder de derogar la Ley ECA de 1972, si así lo resuelve», pasando a repasar los principios doctrinales de siempre sobre el derecho constitucional británico, comenzando por lo que consideró la doctrina líder contenida en el libro del jurista constitucional A.V. Dicey, An Introduction to the Law of the Constitution, donde explicó que el principio de la soberanía parlamentaria significa que el Parlamento tiene:

[...] el derecho de hacer $y$ deshacer cualquier ley; $y$, además, que ninguna persona o entidad está reconocida por la ley [...] como teniendo el derecho de derogar o dejar de lado la legislación del Parlamento ${ }^{12}$.

A juicio de la Alta Corte, esto significa, entre otras cosas, que no puede decirse que una ley sea inválida porque sea opuesta a la opinión del electorado, ya que, como principio legal:

Los jueces no conocen en forma alguna acerca los deseos del pueblo, excepto cuando esos deseos estén expresados en una Ley del Parlamento, y nunca la validez de una ley podrá ser cuestionada basada en que fue sancionada o ha permanecido en vigencia en contraposición a los deseos de los electores ${ }^{13}$.

Este principio de la soberanía parlamentaria, como afirmó la Alta Corte, ha sido reconocido en muchos casos por líderes de la más alta autoridad judicial, por lo cual, como constituye un principio aceptado, se limitó a citar la presentación de lord Bingham of Cornhill en R (Jackson) v Attorney General

12 Cita de la Corte: «p. 38 of the $8^{\text {th }}$ edition, 1915, the last edition by Dicey himself; and see chapter 1 generally».

13 Cita de la Corte: «ibid. pp. 57 and 72». 
[2005] UK HI. 56; [2006] 1 AC 262 at para., en el cual expresó que la «piedra angular de la Constitución británica [...] es la supremacía de la Corona en Parlamento».

\section{SOBRE EL TEMA DE LOS LÍMITES DE LOS PODERES DE PRERROGATIVA DE LA CORONA}

En cuanto a los poderes de la Corona conforme a su prerrogativa (con frecuencia llamados "prerrogativa real»), la Corte se refirió a su extensión, considerando que esos "poderes de prerrogativa constituyen el residuo, en materia de autoridad legal, que se ha dejado en manos de la Corona», citando en apoyo lo afirmado por lord Re en Burmah Oil Co (Burma Trading) Ltd v Lord Advocate [1965] AC 75, at 101:

La prerrogativa es en realidad una reliquia de un tiempo pasado, que no se ha perdido por desuso, pero que es solo disponible en relación con un caso que no se ha convertido en ley (statute).

En relación con dicha prerrogativa, la Corte consideró que un aspecto importante del principio de la soberanía parlamentaria es que la legislación primaria no está sujeta a poder ser suplantada por la Corona mediante el ejercicio de sus poderes de prerrogativa; agregando, además, que los «límites constitucionales» a dichos poderes son incluso más extensos, considerando que la Corona tiene esos poderes de prerrogativa solo cuando los mismos están reconocidos por el common law y su ejercicio solo produce efectos dentro de límites reconocidos por el mismo. Fuera de esos límites, la Corona no tiene poder para alterar leyes, sea que las mismas estén contenidas en el common law o en la legislación.

Esta subordinación de la Corona, y en particular del Gobierno ejecutivo, a la ley, afirmó la Corte, es el fundamento del Estado de derecho en el Reino Unido (is the foundation of the rule of law in the United Kingdom), que tiene sus raíces establecidas mucho antes de la guerra entre la Corona y el Parlamento en el siglo xviI, y que fue definitivamente confirmada, tal como ha sido reconocido desde entonces, en el acuerdo al cual se llegó luego de la Gloriosa Revolución de $1688^{14}$.

14 Véanse los comentarios que sobre ello hicimos en Allan R. Brewer-Carías (2008), Reflexiones sobre la revolución norteamericana (1776), la revolución francesa (1789) y la revolución hispanoamericana (1810-1830) y sus aportes al constitucionalismo moderno, $2^{\text {a }}$ ed. ampliada, Bogotá: Serie Derecho Administrativo 2, Universidad Externado de Colombia, Editorial Jurídica Venezolana. 
En apoyo de esta apreciación, la Corte entonces citó lo que sir Edward Coke refirió como su opinión y la de los jueces reconocidos de la época, sobre el The Case of Proclamations (1610) 12 Co, Rep. 74, en el sentido de que «el Rey con su proclamación o mediante otras vías no puede cambiar parte alguna del common law, ni de las leyes (statute law) ni de las costumbres del Reino», y que "el Rey no tiene prerrogativa alguna, salvo la que la legislación (law of the land) le otorga».

Esto, a juicio de la Alta Corte, fue confirmado en las dos primeras partes de la sección $1^{\text {a }}$ del Bill of Rights de 1688, así:

Poderes de suspensión: que el pretendido poder de suspender las leyes o la ejecución de las leyes por autoridad real, sin el consentimiento del Parlamento, es ilegal.

Poder de dispensar posteriormente: que el pretendido poder de dispensar respecto de las leyes o de la ejecución de las leyes por autoridad real como ha sido asumido y ejercido antes, es ilegal.

Esta posición legal, como lo recordó la Alta Corte, fue resumida por el Privy Council, en el caso The Zamora [1916] 2 AC 77, at 90, así:

La idea de que el Rey en Consejo, o incluso cualquier rama del Ejecutivo, tiene el poder para prescribir o alterar la ley que debe ser aplicada por los tribunales de derecho en este país, está fuera de armonía con los principios de nuestra Constitución. Es cierto que de acuerdo con muchas leyes modernas, varias ramas del Ejecutivo tienen el poder de hacer reglas con fuerza de ley, pero todas esas reglas derivan su validez de la ley (statute) que otorgó dicho poder, y no del órgano ejecutivo que las dicta. Nadie puede cuestionar que la prerrogativa incluye cualquier poder para prescribir o alterar la ley que debe ser aplicada por los Tribunales del Common Law o de Equidad...

La Alta Corte consideró estos principios como generalmente aceptados, estimando innecesario explicarlos con mayor detalle, con base en lo cual analizó el tema de los poderes de la Corona para hacer y deshacer tratados, con efectos reducidos en el ámbito internacional, y sin efectos en el derecho interno, como antes se explicó.

\section{LA INTERPRETACIÓN CONSTITUCIONAL Y EL CONTROL DE CONSTITUCIONALIDAD}

Con ello, la Corte pasó a ejercer su control de constitucionalidad sobre la pretensión del Ejecutivo de formular la notificación prevista en el artículo 50 
del Tratado de la Unión Europea, considerada como una ley constitucional, sin intervención del Parlamento, para lo cual la Corte fijó una serie de criterios sobre interpretación constitucional.

El primero fue el clásico de la presunción de constitucionalidad de los actos del Parlamento, en el sentido de que cuando hay principios constitucionales fuertes, se presume que «el Parlamento legisla en conformidad con los mismos, y no para socavarlos», citando en apoyo múltiples decisiones judiciales, por ejemplo, considerando que hay una fuerte presunción contra la afirmación de que el Parlamento haya tenido la intención de dar efecto retroactivo a alguna previsión legal, incluso si el lenguaje usado en la ley pueda hacer pensar que se trataba de crear dicho efecto; así como en cuanto a los efectos territoriales de las leyes. También hay una fuerte presunción de que el Parlamento no puede intentar limitar el acceso a los tribunales ordinarios para determinadas disputas ${ }^{15}$. La Alta Corte continuó su argumento indicando que:

Todas estas presunciones podrían ser eliminadas por el Parlamento si así lo decide, pero mientras más fuerte es el principio constitucional, más fuerte es la presunción de que el Parlamento no intentó revocarlo, y más fuerte será el material requerido, en términos de lenguaje expreso o de clara implicación necesaria, antes de que se pueda propiamente deducir que efectivamente lo intentó. En sentido similar, mientras más fuerte sea el principio constitucional, más fácilmente se puede deducir que las palabras usadas por el Parlamento estaban destinadas a desarrollar el sentido que refleja el principio.

Este argumento interpretativo era importante, a juicio de la Alta Corte, porque el secretario de Estado en su argumento, al interpretar la Ley ECA de 1972, dejando fuera parte de los antecedentes constitucionales mencionados, argumentó que eran los recurrentes quienes tenían que identificar el lenguaje

15 Citas de la Corte: «see, for example, Anisminic Ltd v Foreign Compensation Commission [1969] 1 AC 147. Another example, debated at some length at the hearing, is the principle of legality, i.e. the presumption that Parliament does not intend to legislate in a way which would defeat fundamental human rights: see R v Secretary of State for the Home Department, exp. Pierson [1998] AC 539 at 573G, 575B-G (Lord BrowneWilkinson) and $R \mathrm{v}$ Secretary of State for the Home Department, exp. Simms [2000] 1 AC 115, 131D-G (Lord Hoffmann). see, for example, Anisminic Ltd v Foreign Compensation Commission [1969] 1 AC 147. Another example, debated at some length at the hearing, is the principle of legality, i.e. the presumption that Parliament does not intend to legislate in a way which would defeat fundamental human rights: see R v Secretary of State for the Home Department, exp. Pierson [1998] AC 539 at 573G, 575B-G (Lord Browne-Wilkinson) and $R \mathrm{v}$ Secretary of State for the Home Department, exp. Simms [2000] 1 AC 115, 131D-G (Lord Hoffmann)». 
expreso en la Ley que eliminaba a la Corona su prerrogativa en relación con la conducción de las relaciones internacionales en nombre del Reino Unido. Es decir, el secretario de Estado formuló su defensa alegando que era necesario encontrar en la Ley ECA de 1972 un lenguaje expreso y en todo caso claro, antes de que pudiera deducirse que el Parlamento tuvo la intención de suprimir el poder de prorrogativa de la Corona para tomar los pasos necesarios para sacar al Reino Unido de las Comunidades Europeas y del Tratado de la Unión Europea.

Para formular este argumento, a juicio de la Corte, el secretario de Estado, al analizar la Ley ECA de 1972, no le dio valor alguno al principio constitucional de que, excepto cuando el Parlamento legisle lo contrario, la Corona, ejerciendo sus poderes de prerrogativa, no debe tener poder para variar la legislación (the law of the land).

La Alta Corte, en consecuencia, desestimó los argumentos del secretario de Estado basándose en dos principios constitucionales.

Primero, el principio de que la Corona no puede hacer uso de sus poderes de prerrogativa para alterar la legislación doméstica, el cual, a juicio de la Alta Corte, es producto de una fuerte tradición constitucional en el Reino Unido y de las democracias que siguen la tradición ${ }^{16}$. El principio evolucionó a través de la gran lucha antes mencionada que aseguró la soberanía parlamentaria y restringió los poderes de prerrogativa de la Corona. Por ello, consideró la Alta Corte que habría sido sorprendente, a la luz de esa tradición, que el Parlamento como cuerpo soberano conforme a la Constitución, hubiera tenido la intención de abandonar la continuada existencia de los derechos que introdujo en el derecho interno al poner en vigor la Ley ECA de 1971, dejándolo a la escogencia de la Corona en ejercicio de sus poderes de prerrogativa, en el sentido de permitir que los Tratados de la Comunidad pudieran continuar aplicándose o sacar al Reino Unido de ellos. Agregó la Alta Corte, como lord Browne-Wilkinson lo expresó en $R v$ Secretary of State for the Home Department, exp. Fire Brigades Union [1995] 2 AC 513 at 552E, que:

Corresponde al Parlamento, no al Ejecutivo, derogar la legislación. La historia constitucional de este país es la historia de la sujeción de los poderes de prerrogativa de la Corona a los superiores poderes de la legislatura democráticamente electa como cuerpo soberano.

En este contexto, la Alta Corte también consideró que era relevante tener en cuenta el profundo efecto que el Parlamento quiso que la sanción de la Ley ECA 1972 tuviera en el derecho interno, lo que precisamente condujo a

16 Cita de la Corte: «see for example the New Zealand decision in Fitzgerald $v$ Muldoon [1976] 2 NZLR 615 at 622)». 
que se la identifique como una ley con un especial significado constitucional (statute of special constitutional significance), por lo cual, por los profundos y extendidos cambios legales que produjo, es especialmente improbable que el Parlamento hubiera tenido la intención de dejar su existencia en las manos de la Corona a través del ejercicio de sus poderes de prerrogativa. Habiendo el Parlamento tomado el paso mayor de establecer el efecto directo y prevalente del derecho de la Unión Europea en el sistema legal nacional, sancionado la Ley ECA de 1972 como legislación primaria, no es plausible suponer que tuvo la intención de que la Corona pudiera, a través de su propia acción unilateral bajo sus poderes de prerrogativa, eliminar dicho efecto.

Incluso, precisó la Alta Corte, que la Ley ECA de 1972, como ley constitucional, es de tal naturaleza, que se considera que el Parlamento la exceptuó de la aplicación de la doctrina usual de la derogación implícita mediante la sanción de legislación posterior que fuera inconsistente con la misma ${ }^{17}$. Al contrario, la Ley solo puede ser derogada en alguna parte, solo si el Parlamento expresa en una forma clara en una legislacion posterior tal derogatoria, es decir, que eso es lo que quiere hacer. La Alta Corte concluyó afirmando que:

[...] si desde que la Ley ECA de 1972 se sancionó como ley constitucional de gran importancia, el Parlamento ha indicado que debe quedar exento de derogaciones casuales implícitas por el mismo Parlamento, mucho menos puede pensarse que el Parlamento tuvo la intención de que sus efectos legales pudieran ser eliminados por la Corona a través de sus poderes de prerrogativa.

El segundo principio constitucional al que se refirió la Corte para decidir, fue el antes mencionado de que los poderes de prerrogativa de la Corona solo operan en el plano internacional, y que esos poderes no tienen efectos en el derecho interno, siendo un principio aceptado por los tribunales que este es un campo de acción dejado a la Corona sin la interferencia del Parlamento. Pero la justificación para una presunción de no interferencia con los poderes de prerrogativa de la Corona en la conducción de las asuntos internacionales, consideró la Alta Corte que está sustancialmente reducida en un caso como el decidido en la sentencia, en el cual el secretario de Estado, al contrario, mantuvo que él podía, mediante el ejercicio de los poderes de prerrogativa de la Corona, introducir cambios mayores en la legislación interna, lo cual fue rechazado por la Corte.

De allí la conclusión de la Alta Corte al interpretar la Ley ECA de 1972 a la luz de los antecedentes constitucionales antes mencionados, que la in-

17 Cita de la Corte: «see Thohurn v Sunderland City Council, at [60]-[64], and section 2(4) of the ECA 1972». 
tención del Parlamento al sancionar dicha Ley e introducir el derecho de la Unión Europea en el derecho interno fue que ello no pudiera ser deshecho por la Corona mediante el ejercicio de sus poderes de prerrogativa. Es decir, que con la sanción de la Ley ECA de 1972, la Corona no tiene poder de prerrogativa alguno para decidir la salida del Reino Unido de los Tratados de la Comunidad y afectar los derechos de los ciudadanos derivados de los mismos, efectuando la notificación establecida en el artículo 50 del Tratado de la Unión Europea; rechazando en consecuencia los argumentos del secretario de Estado.

Por último, la Alta Corte se refirió a la Ley del Referendo de la Unión Europea de 2015, estando de acuerdo con el hecho de que el secretario de Estado no haya argumentado que la misma supuestamente le daba un poder estatutario a la Corona para efectuar la notificación conforme al artículo 50 del Tratado de la Unión Europea, pues de haberlo hecho era insostenible en materia de interpretación legal.

Dicha Ley del Referendo de 2015 tiene que ser interpretada, a juicio de la Alta Corte, a la luz de los principios constitucionales básicos de la soberanía parlamentaria y de la democracia representativa que se aplican en el Reino Unido, lo que la llevó a la conclusión de que «un referéndum en cualquier materia solo puede tener efectos de recomendación para los legisladores en el Parlamento, excepto cuando un lenguaje claro en contrario se use en la legislación sobre el referendo en cuestión", lo que no se encuentra en el texto de la Ley del Referendo de 2015.

Incluso, en el caso del referendo de 2015, la Alta Corte recordó que la Ley respectiva:

[...] fue adoptada sobre la base de un documento claro enviado a los parlamentarios de que el referendo tendría solo efectos de recomendación. Incluso el Parlamento debió haber apreciado que el referendo estaba destinado solo a ser consultivo, ya que el resultado de un voto en el referendo a favor de la salida de la Unión Europea hubiera inevitablemente dejado para futura decisión muy importantes cuestiones relativas con la implementación legal de dicha salida de la Unión Europea.

En todo caso, concluyó la Alta Corte en su sentencia, que «no cuestionaba la importancia del referendo como evento político, cuya significación tendrá que ser considerada y tomada en cuenta en otra parte», decidiendo finalmente que «el Secretario de Estado no tiene poder conforme a la prerrogativa de la Corona, para formular la notificación conforme al artículo 50 del Tratado de la Unión Europea para la salida del Reino Unido de la misma». 


\section{LA CONFIRMACIÓN DE LA DECISIÓN DE LA ALTA CORTE DE JUSTICIA POR LA CORTE SUPREMA DEL REINO UNIDO}

La Sentencia de la Alta Corte de Justicia del 3 de noviembre de 2016, luego de haber sido apelada por el Gobierno, fue confirmada por la Corte Suprema del Reino Unido en sentencia dictada con una mayoría de 8 a 3, el 24 de febrero de 2016 (Caso: $R$ (on the application of Miller an another) $v$ Secretary of State for Exiting the European Union) ([2017 UKSC 5) (UKSC 2016/0196) ${ }^{18}$, ratificando que, en el caso, se requiere de un Acto del Parlamento que autorice a los ministros para poder enviar la notificación de la decisión del retiro del Reino Unido de la Unión Europea.

Debe indicarse que con posterioridad a la decisión de la Alta Corte del 3 de noviembre de 2016, y de haberse intentado la apelación, el 7 de diciembre de 2016, la Cámara de los Comunes adoptó una resolución llamando a los ministros a enviar para el 31 de marzo de 2017, conforme al artículo 50 de los Tratados, la notificación respectiva sobre el retiro del Reino Unido de la Unión Europea. Esto, sin embargo, a juicio de la Corte Suprema, con lo que estuvo de acuerdo el Gobierno en el proceso, fue solo un acto político que no afectó en forma alguna las cuestiones que surgieron de las apelaciones en el proceso.

Entre esas cuestiones, la principal que se consideró para la decisión de alzada fue la consideración por la Corte Suprema de que los términos de la Ley ECA de 1972, que dio efectos a la membresía del Reino Unido en la Unión Europea, son inconsistentes con la pretensión de ejercicio de cualquier poder por parte de los ministros de sacar al Reino Unido de los Tratados de la Unión Europea, sin la autorización previa del Parlamento.

A juicio del Tribunal, la sección 2 de la Ley ECA de 1972 autorizó un proceso dinámico a través del cual el derecho de la Unión Europea se convirtió en fuente del derecho del Reino Unido, con aplicación preferente sobre todas las otras fuentes de derecho nacionales del mismo, incluyendo las leyes (statutes). Por tanto, mientras la Ley ECA de 1972 permanezca en vigencia, sus efectos son los de constituir al derecho de la Unión Europea como una fuente independiente y prevalente en el derecho nacional. Con la misma, estimó la Corte Suprema, se produjo una transferencia parcial de poderes de legislar (law-making powers), de asignación de competencias legislativas por el Parlamento a las instituciones de la Unión Europea, salvo y hasta cuando el

18 Véase el texto de la sentencia en https://www.supremecourt.uk/cases/docs/uksc2016-0196-judgment.pdf. Véase la información de prensa sobre la sentencia en https://www.supremecourt.uk/cases/docs/uksc-2016-0196-press-summary.pdf. 
Parlamento decida otra cosa. Ello implica que la ley interna en el Reino Unido cambiará si el mismo deja de ser un Estado miembro de los Tratados de la Unión Europea, y que los derechos derivados del derecho comunitario de los que gozan los residentes del Reino Unido se verán afectados.

La Corte Suprema analizó el argumento del Gobierno de que la Ley ECA de 1972 no había excluido el poder de los ministros de poder sacar al Reino Unido de los Tratados de la Unión Europea, y que la sección 2 de la Ley prevé el ejercicio de tal poder al dar efecto al derecho de la Unión Europea solo y hasta que el poder de decidir la salida no sea ejercido. Sin embargo, la Corte Suprema indicó que hay una vital diferencia entre las variaciones que puedan producirse en el derecho del Reino Unido como resultado de los cambios en el derecho de la Unión Europea, y las variaciones que se pueden producir como resultado de la salida de los Tratados de la Unión Europea. En este último caso, si se presenta la notificación respectiva, el efecto inevitable sería en realidad un cambio fundamental en el marco constitucional del Reino Unido, pues ello significaría la eliminación de las fuentes del derecho de la Unión Europea en el orden interno.

A juicio de la Corte Suprema, un cambio de tal naturaleza en la constitución del Reino Unido requiere que sea efectuado a través de legislación parlamentaria. Además, el hecho de la salida del Reino Unido de la Unión Europea implica la eliminación de algunos derechos domésticos de los que gozan los residentes en el Reino Unido, lo que hace que sea imposible que el Gobierno pueda decidir la salida de los Tratados de la Unión Europea sin la autorización previa del Parlamento.

Por supuesto, el Parlamento, cuando sancionó la Ley ECA de 1972, pudo haber autorizado a los ministros para decidir la salida del Reino Unido de los Tratados de la Unión Europea, para lo cual, sin embargo, hubieran tenido que prever con claridad dicha posibilidad en el texto expreso de la Ley, lo cual no ocurrió. Al contrario, no solo no hay palabras claras sobre ello, sino que las previsiones de la propia Ley ECA de 1972 indican que los ministros no tienen tal poder. Y el hecho de que los ministros sean responsables ante el Parlamento por sus acciones, no es ninguna respuesta constitucional útil para resolver el tema planteado, particularmente si el poder para actuar no existe, y si la decisión vaciaría irrevocablemente al propio Parlamento de poder actuar ${ }^{19}$.

En todo caso, a juicio de la Corte Suprema, la legislación subsecuente relacionada con la Unión Europea dictada con posterioridad a 1972, incluyendo la introducción de controles parlamentarios en relación con las decisiones

19 Cita de la Corte: «The Supreme Court of the United Kingdom Parliament Square London SW1P 3BD T: 0207960 1886/1887 F: 02079601901 www.supremecourt.uk». 
adoptadas por los ministros a nivel de la Unión Europea, en relación con las competencias de la misma o en su proceso de elaboración de normas comunitarias, aun cuando no para presentar la notificación revista en el artículo 50 de los Tratados, son completamente consistentes con la asunción por el Parlamento de que no hay poder alguno para decidir la salida del Reino Unido de los Tratados sin una ley (statute) autorizándola.

Por último, la Corte Suprema en su sentencia también se refirió al referendo de 2016, considerando que si bien fue un evento de gran importancia política, su significado legal fue el establecido por el Parlamento en la Ley autorizando su realización, y en la Ley simplemente se previó su realización, pero no se especificaron sus consecuencias. En consecuencia, consideró la Corte Suprema que los cambios en la ley que requiera la implementación del resultado del referendo solo pueden efectuarse en la única forma permitida por la constitución del Reino Unido, que es mediante legislación.

La conclusión de todo este proceso constitucional desarrollado ante los órganos con competencia para ejercer la jurisdicción constitucional en el Reino Unido fue, por tanto, que la salida del mismo de los Tratados de la Unión Europea solo puede resolverse mediante una ley del Parlamento que así lo decida, no teniendo efecto jurídico constitucional alguno la recomendación política expresada en el referendo de 2016.

Ese fue el criterio expresado en sus sentencias, tanto por la Alta Corte de Justicia como por la Corte Suprema del Reino Unido, en un proceso de control de constitucionalidad, rechazando la posibilidad de que el Ejecutivo pudiera tener competencia alguna para tomar esa decisión sin la autorización previa del Parlamento.

\section{LA DESESTIMACIÓN DE LOS ALEGATOS SOBRE DEVOLUTION EN RELACIÓN CON LA CUESTIÓN DE LA INJERENCIA DE IRLANDA DEL NORTE, ESCOCIA Y GALES EN LA DECISIÓN SOBRE EL BREXIT}

Por último, debe mencionarse que si bien en el caso desarrollado en primera instancia ante la High Court el tema debatido en la materia fue solo el de determinar si para la salida del Reino Unido de la Unión Europea era necesaria o no la intervención previa del Parlamento de Westminster, que autorizara al Gobierno para proceder en tal sentido, ello analizó sin referencia alguna a si los Parlamentos de las diversas naciones que componen el Reino Unido también debían decidir algo al respecto.

Este último tema, sin embargo, sí se planteó en segunda instancia ante la Corte Suprema, mediante diversos planteamientos referidos, entre otros, por 
el Attorney General de Irlanda del Norte, y otros formulados en intervenciones por el Lord Advocate del Gobierno de Escocia y el Counsel General de Gales, por el Gobierno de Gales, en los cuales se formularon como cuestiones adicionales ante la Corte la de determinar si conforme a los poderes que legalmente han sido descentralizados (statutorily devolved) ${ }^{20}$ a las naciones del Reino Unido, también se requería para la salida del Reino Unido de la Unión Europea de una consulta o acuerdo de las legislaturas descentralizadas (devolved legislatures) antes de que el Gobierno pudiese formular la notificación prevista en el Tratado de la Unión Europea, como una restricción al poder del Gobierno.

Estas devolution issues, como las denominó la Corte Suprema, le exigieron considerar si en los términos del Northern Ireland Act 1998 (NIA) ${ }^{21}$, y de los acuerdos asociados con el mismo (Belfast Agreement y British-Irish Agreement), se requería de una legislación primaria y del consentimiento de la Northern Ireland Assembly y/o del pueblo de Irlanda del Norte antes de que la notificación fuera formulada, lo cual consideró la Corte Suprema partiendo del supuesto de que:

Conforme a cada devolution settlements en Irlanda del Norte, Escocia y Gales las legislaturas descentralizadas (devolved legislatures) tienen la responsabilidad de cumplir con el derecho de la Unión Europea, existiendo una convención constitucional (the Sewel Convention) que impone que el Parlamento del Reino Unido normalmente no ejerce sus poderes para legislar en relación con las materias descentralizadas (devolved matters) sin el acuerdo de las legislaturas descentralizadas.

En relación con estas devolution issues, la Corte Suprema fue precisa en considerar que cuando se establecieron esas restricciones relativas a la Unión Europea en el Northern Ireland Act y en las otras devolution Acts, el Parlamento se basó en la asunción de que el Reino Unido permanecería como miembro de la Unión Europea, siendo ello consistente con considerar que solo le corresponde el Parlamento determinar esa permanencia. Pero al imponerse dichas restricciones mediante la devolution legislation, otorgándosele poder a las devolved institutions de observar e implementar el derecho de la Unión Europea,

20 Sobre el concepto británico de devolution en el marco general de la regionalización/ descentralización políticas, véanse Allan R. Brewer-Carías (1977), "Regionalization in Economic Matters in Comparative Law,» en Rapports Generaux au IX Congrés International de Droit Comparé, Teherán 1974, Bruselas, págs. 669-696; (1983), «La descentralización territorial: Autonomía territorial y regionalización política», Revista de Estudios de la Vida Local, 218 (Madrid: Instituto de Estudios de Administración Local), págs. 209-232.

21 Véase en http://www.legislation.gov.uk/ukpga/1998/47/contents. 
ello no implicó que el Reino Unido debía permanecer como miembro de la Unión Europea. En el Reino Unido, a juicio de la Corte Suprema, las relaciones con la Unión Europea, como en otras materias relativas a las relaciones exteriores, están reservadas al Gobierno del Reino Unido o exceptuadas en el caso de Escocia e Irlanda del Norte, y no fueron descentralizadas en el caso de Gales ${ }^{22}$, por lo que consideró que las legislaturas descentralizadas no tienen una competencia legislativa paralela alguna en relación con la salida del Reino Unido de la Unión Europea.

La Corte Suprema precisó además que, en el caso de Irlanda del Norte, lo que las previsiones del Belfast Agreement de $1998^{23}$ dieron al pueblo de Irlanda del Norte fue el derecho de determinar si dicha nación permanecía siendo parte del Reino Unido o si pasaban a ser parte de una Irlanda unida, no existiendo en ninguna ley constitucional de Irlanda del Norte nada que pudiera significar requerir el consentimiento de la mayoría del pueblo de Irlanda del Norte para la decisión sobre la salida del Reino Unido de la Unión Europea.

En cuanto a la mencionada Sewel Convention ${ }^{24}$, la Corte Suprema precisó que la misma, a la cual le reconoció la característica de convención constitucional, fue adoptada como un mecanismo para establecer una relación de cooperación entre el Parlamento del Reino Unido y los parlamentos nacionales (devolved institutions), en particular en casos de competencias legislativas superpuestas. En virtud de que el Parlamento de Westminster se había reservado en cada uno de los convenios de descentralización (devolution settlements) su derecho de legislar en las materias que caen bajo la competencia de las legislaturas descentralizadas, mediante la Sewel Convention lo que se previó fue solo que «el Parlamento del Reino Unido no procedería normalmente a legislar sobre las materias descentralizadas (devolved matters) excepto con el acuerdo de las legislaturas descentralizadas».

De ello, la Corte Suprema concluyó, en definitiva, que no habiendo sido las relaciones entre el Reino Unido y la Unión Europea una materia que hubiese sido descentralizada, los parlamentos nacionales no tenían derecho de veto legal alguno respecto de la decisión de la salida del Reino Unido de la Unión Europea, como lo reconocieron en el proceso los abogados de Escocia

22 Cita de la Corte: «see section 30(1) of, and paragraph 7(1) of Schedule 5 to, the Scotland Act 1998; section 108(4) of, and Part 1 of Schedule 7 to, the Government of Wales Act 2006; and section 4(1) of, and paragraph 3 of Schedule 2 to, the NI Act. 130».

23 Véase en https://www.gov.uk/government/uploads/system/uploads/attachment_data/ file/136652/agreement.pdf.

24 Véase en http://researchbriefings.parliament.uk/ResearchBriefing/Summary/ SN02084\#fullreport. 
y Gales, lo que igualmente aplicó al caso de Irlanda del Norte, desechando los devolution issues presentados en segunda instancia, declarando en consecuencia que no se requiere del consentimiento de las legislaturas de Irlanda del Norte, Escocia y Gales para que el Parlamento sancione la ley respectiva exigida para autorizar al Gobierno para formular la notificación sobre la salida del Reino Unido de la Unión Europea. 